\title{
Estéticas da diversão nos "mortos-vivos" contemporâneos"
}

\author{
Marília Etienne Arreguy* \\ Universidade Federal Fluminense. Niterói, RJ, Brasil
}

Resumo: O presente ensaio visa refletir sobre a diversão com uma estética da violência nos cult movies e alguns de seus efeitos na subjetividade contemporânea. Toma por base o referencial psicanalítico cotejado com a perspectiva crítica de Theodor Adorno. $\mathrm{O}$ texto utiliza o conceito de diversão como fonte de crítica à indústria cultural, no intuito de demonstrar o modo em que certa estética da violência produz uma espécie de sublimação passiva e alienante em boa parte dos sujeitos, que passam a representar, sobretudo do ponto de vista político, uma espécie de "mortosvivos", ou seja, de zumbis impotentes, como atestam as análises de Slavoj Žižek. O filme Funny games [Violência gratuita] de Michael Haneke ilustra essa análise.

Palavras-chave: diversão, violência, mortos-vivos/não mortos, psicanálise, cult movies.

Violence became domesticated in its image and the pleasant chill of horror administered in homeopathic dosages was quite welcome. The controlled invocation of evil permitted the hope for its controllability in reality. The form-content relation of classical aesthetics appears to have become obsolete. The morality of selling has little in common with that of a possible social contract. (Haneke, 2010, p. 578)

Pretendo falar sobre a incidência de uma estética da violência na produção de subjetividades contemporâneas tendo em vista a afecção causada pelos "cult movies". A base dos argumentos usados nesse ensaio provém da Psicanálise em interação com outros saberes, especificamente na apropriação do conceito de "diversão" delimitado por Adorno, mas também na Filosofia pop de Žižek, em sua leitura do objeto a lacaniano, e na noção de "mortos-vivos", os zumbis contemporâneos. Com isso, pretendo propor uma interpretação do recurso estético de exposição da imagem do corpo no instante da morte, que configura certa tipicidade às usuais cenas de assassinato no cinema atual. As imagens de despedaçamento do corpo fazem parte da cultura e, portanto, requerem hipóteses sobre sua motivação e funcionalidade. Em que medida os espectadores dos cult movies seriam passivos, desmotivados, alienados num tipo de cultura em que não têm capacidade de transformação, logo, agem como se fossem zumbis, sanguessugas, ou ainda, mortos-vivos, que se prestam a consumir e a gozar de imagens traumáticas de violência? A oferenda de gozo barato da indústria cultural não seria uma forma de paralisar o sujeito num gozo abjeto e desmotivado? Até que ponto diversão e crítica se opõem?

1 Texto elaborado a partir da palestra apresentada na mesa redonda "Corps Réconfiguré" no Colloque Internationale Subjectivités et Montages Corporelles dans le Monde Contemporain realizado na Universidade Federal do Rio de Janeiro, em maio de 2013.

* Autora correspondente: mariliaetienne@id.uff.br
A análise do "desalento" do "sujeito contemporâneo", elaborada por Birman (2012), fornece elementos adicionais na compreensão dessa "estética da diversão" nos cult movies, a saber, a espacialização da experiência da dor expressa nas figuras de corpos destroçados estampados nas telas, assim como a redução da temporalidade ao instante da morte. Para Birman (2012), uma das características marcantes que unifica a subjetividade atual seria justamente a redução da vida a categorias extensivas, ou seja, a aspectos materiais e concretos, inflacionando a dimensão "espacial" em que o corpo e suas estéticas estariam sempre em primeiro plano. Soma-se a isso, um empobrecimento da experiência "temporal", com a perda de perspectivas de futuro e o esvaziamento dos valores do passado, de modo a atuar numa espécie de "presente perpétuo", conforme Jameson (1990/1993) já descrevera ao falar da pós-modernidade.

A multiplicação das cenas de violência explícita é apresentada nos mais diversos níveis de cinematografia, desde os filmes de terror ou de zumbis representados pelos "mortos-vivos" de Romero (1978), passando pela estética dos quadrinhos (Sin city, 2005), pela sátira de Tarantino (Kill Bill, 2003; Pulp Fiction, 1994), pelos enlatados de super-heróis redentores, pelos inúmeros filmes de guerra, aprimorando formas cada vez mais sutis de exploração da angústia do espectador.

É evidente que diferentes gêneros do cinema convivem independentemente, na proporção que recorrem amplamente à violência como um atrativo de marketing garantindo o aumento de bilheteria. É também fato que desde a invenção do gore, ou seja, dos filmes que expõem diretamente cenas de sexo e de morte, tornou-se cada vez mais presente a destruição tácita do corpo como forma de produzir um clímax banalizado e repetitivo. Em contraposição aos antigos thrillers de suspense, esse movimento representa o auge da passagem dos romances de enigma baseados na necessidade de velar a história, fisgando o espectador pela curiosidade cognitiva, para um período de 
predominância do roman noir em que a exposição mórbida do corpo bem como a explicitação do sexo passam a ser as premissas que garantem o interesse por uma narrativa literária ou fílmica (Massat-Hessel, 2006).

O ponto a ser considerado é que, de alguma maneira, o cinema enquanto expressão de uma arte mais acessível, fruto da indústria cultural, rouba da plateia um a mais de gozo, ao imprimir um ritmo intenso, imediatista e frenético, para o regime das pulsões. Supomos que essa estética de consumo da violência obtém sucesso justamente por propiciar a negação do sofrimento, referido à eliminação da consciência do dever político e crítico, na medida em que se projeta (na tela e no sujeito) um exercício e, até, um elogio da violência. Seguindo a análise de Birman (2012), no lugar do sofrimento advém a dor, vivida na sensação corpórea a ser administrada pelo público. O mal-estar deve se tornar diversão, já que a transformação pulsional pela qual o espectador passa ao assistir aos filmes violentos não pode ser chamada apenas de catártica. Há uma reprodução dessa estética à medida em que, principalmente os jovens, consomem uma série de subprodutos, vestimentas, músicas, um estilo de andar e gesticular, uma linguagem específica dos guetos, fazendo da diversão um trabalho de consumo, e da dor, um elemento a ser cultuado, algo que outrora chamei de "sublimação passiva" (Arreguy, 2012). Ao mesmo tempo que encontra a "diversão", como uma expressão de seu desejo, o sujeito contemporâneo é levado a um movimento paradoxal no âmago de sua alienação. $\mathrm{O}$ sujeito se diverte com a cena e diverge da cena, à medida em que espectador e filme representam um mesmo fenômeno. $\mathrm{O}$ " $\mathrm{x}$ " da angústia do espectador é mobilizado por um gesto de "repulsa" ineficaz, quando desvia seu olhar dos destroços mórbidos espalhados no plano da imagem. Essa dinâmica envolve, do lado da imagem, a espacialização do corpo como "objeto a/abjeto", e, do lado da plateia, a "diversão" situada entre a angústia e o desejo, coartado pela paralisação do tempo em imagens excessivas. Assim, a angústia surge como vazio do afeto provocado pela encenação do objet petit $a$ na exposição de vestígios corporais, restantes da encenação da morte. Afinal, ao menos na parcela neurótica da audiência, a angústia seria prevalente. $\mathrm{Na}$ visada perversa, o olhar direto e fixado seria uma expressão direta do gozo.

Ilustrarei alguns desses aspectos por meio do thriller Funny Games [Violência Gratuita] (1997), refilmado em 2007, por Michal Haneke. A primeira versão ganhou o prêmio Fripesci em Cannes. O remake foi gravado na íntegra, mantendo-se absolutamente fiel ao roteiro original. Se pudéssemos categorizar a dialética proposta pela arte de Haneke, seria a extração de afetos extremos que vão da ilusão de onipotência à castração absoluta. Ao passo que a maioria dos cult movies são categorizados como "enlatados", ou seja, de valor artístico duvidoso, diante dos quais o sujeito contemporâneo seria apenas um espectador passivo, Violência gratuita convoca a uma reflexão, pois usa um instrumental semelhante, salientando a condição bizarra da sedução pela violência.
A sinopse do filme é bem simples: uma família de classe A, composta por pai, mãe, filho e cachorro², vai passar o fim de semana em sua mansão do lago, para pescar e jogar golfe. Quando chegam, passam na casa de um de seus vizinhos e são apresentados a dois rapazes muito educados, ambos vestidos de branco (short, camiseta e luvas). Subsequentemente, os rapazes entram polidamente na propriedade para pedir ovos "emprestados", numa típica situação de vizinhança amigável. Um deles começa a provocar a impaciência da dona da casa, ao derrubar os ovos repetitivamente no chão. Além disso, Peter, o abobalhado cúmplice do perverso Paul, derruba "sem querer querendo" o celular da mulher dentro da pia, inutilizando-o. Para caracterizar os vilões, diríamos que Paul assume a paradoxal postura de um polido pai tirânico, e Peter, seu cúmplice, inferiorizado, aparece como um sádico meio débil, meio atávico. Peter sustenta a ficção, ao passo que Paul se dirige diversas vezes diretamente ao público, de certa forma incluindo o espectador na trama.

No decurso da história, os rapazes dão sequência a um joguete, em que qualquer manifestação de contrariedade das vítimas, ou seja, da família atacada, passa a ser punida exemplarmente pelos rapazes. O cachorro é assassinado porque late, o marido tem seu joelho quebrado com uma tacada de golfe ao dar um tapa no rosto de Paul, quando tenta inutilmente expulsar os, até então, apenas "garotos" travessos. Paul vira-se para a câmera e dá um sorriso malicioso para o público, "quebrando o quarto muro". E, assim, de um modo ironicamente sádico, Paul convida os personagens (e a plateia) a participar de uma aposta, ou seja, indaga ao público se até a manhã do dia seguinte todos estarão vivos ou mortos. A sequência de cenas é frequentemente interrompida, com explicações de Paul, por exemplo, quando o pai, George, lhe pergunta: "Por que ele está fazendo isso? Por que não os mata de uma vez?", Paul responde: "Porque senão não haveria graça, aliás, ainda não atingimos a duração necessária de um longa-metragem.”

Situada do lado do espectador, a pergunta atravessada da ficção para a realidade permite colocar o sujeito do lado de um "morto-vivo", que goza da posição passiva da ficção, mas também, que tem, tanto suas pulsões agressivas e destrutivas, quanto sua (im)potência, mobilizadas. Ora, no filme Funny games, ao meu ver, melhor traduzido, simplesmente por "Jogos divertidos", Michael Haneke "quebra a quarta parede" propositalmente ao imiscuir realidade e ficção, invocando o espectador a participar ativamente da cena com sua angústia, mas sobretudo com seu desejo de transformar a realidade do filme, e redimir-se. Quando Paul, um dos delinquentes invasores, olha para a plateia e diz: "o que vocês apostam, que a família sobreviverá ou não?", Haneke inverte a lógica identificatória e moralizante dos cult movies ideológicos. Pois, ao vermos filmes hollywoodianos de ação violenta, sobretudo aqueles com mocinhos hiperpotentes ou super-heróis idealizados,

\footnotetext{
2 Para conhecimento da história e personagens, ver dados disponíveis na internet: http://en.wikipedia.org/wiki/Funny_Games_\%281997 film $\% 29$.
} 
sabemos que haverá derramamento de sangue, porém o gozo com a violência, em geral vem combinado à redenção moral final, suturando a angústia e satisfazendo parcialmente o desejo idealizado. Assim, a imagem se interpõe como um recurso de velar os aspectos fictícios e iludir o auditório. Contudo, Haneke faz isso pela via oposta, desvelando a ficção, abrindo um furo na realidade inverossímil e eliciando o Real pulsional. Nos cult movies enlatados o gozo é garantido e a culpa, atenuada. Haneke, do contrário, não oferece redenção. Inverte os elementos, tornando a ficção aparente, nitidamente por meio da metalinguagem que inclui o espectador na trama. Ele abre a angústia e frustra o desejo, tornando a arte da ficção, um instrumento de crítica e apreensão de um sintoma social, indiscernível à temporalidade subjetiva imediata. $\mathrm{O}$ diretor cria então um hiato, com a impressão de um potencial traumático à cena, a ser elaborado, talvez, só depois.

No documentário The Pervert's Guide to Cinema, Slavoj Žižek (2005) afirma: "Se queres conhecer a realidade, analise o cinema". Segundo essa lógica, não seriam os "jogos de diversão" uma ilustração perfeita dessa curva que compõe o Real, amalgamando imagem e realidade? Žižek (2008a) busca definir o Real lacaniano: "Enquanto a realidade é aquilo que permanece igual lá fora e percebemos de um modo que é sempre parcial, distorcido, o Real é a própria causa dessa distorção, o X que faz com que nossa percepção da realidade seja sempre distorcida." (p. 97). Para além da clássica divisão kantiana entre perceptum e percepiens, o numenal e o fenomenal, a coisa-em-si (Das Ding) e aquilo que dela captamos, o Real é justamente mais um que se coloca entre esses dois aspectos, impedindo inexoravelmente uma tradução entre os extremos, mas também, unificando-os. Nesse sentido, o filme se assemelha à atmosfera de sonho, em que cremos estar sujeitos a algo inescapável, porém, suposta e simultaneamente, mutável, pois também comporta a ilusória capacidade de ação subjetiva, que (re)cria o Real pelo viés da fantasia. Se por um lado, é pura ficção, por outro, o filme é percebido como pura realidade. A arte da tela, assim, é o que unifica dois "mundos" incomunicáveis. Em outras palavras, Žižek (2008a) indaga: "E o cinema não é o exemplo supremo do fluxo estéril do devir da superfície? A imagem cinematográfica é inerentemente estéril e impassível, o efeito puro de causas corpóreas, embora adquira, apesar de tudo, sua pseudoautonomia" (p. 42).

O filme provoca um efeito de suspensão, mais que de tensão, interpelando o sujeito quanto aos efeitos potenciais desses embates violentos no seu corpo. Em que o espectador pode se implicar com o roteiro? Seria um desperdício de sua energia "torcer" pelo final feliz? Até que ponto os jogos de diversão, de Haneke, podem motivar entretenimento ou, na contramão dos fatos, exigiriam um trabalho psíquico? Não parece à toa a imbricação entre as cenas do cinema e os assassinatos cometidos em massa por adolescentes que entram atirando em salas de cinema e em instituições de educação mundo afora. Os ataques a princípio imotivados teriam por ventura alguma baliza nos mecanismos sociais de violência simbólica ou nas cenas sacrificiais repetidas ad infinitum nos cult movies? A ficção de Haneke não representaria justamente o índice dessa realidade cotidiana globalizada que nos acossa de modo estéril e impassivel? É como se, pela via da imagem, pudéssemos ler a paródia do mandamento bíblico feita por Žižek (2008, p. 40, tradução nossa): Tema a teu próximo como a ti mesmo [Fear thy neighbour as thyself]. Essa proposição assinala a tradição crítica de pensamento adotada pelo autor, desmistificando perspectivas maniqueístas que buscam escamotear, silenciar ou distorcer uma leitura sobre a condição agressiva vital do ser humano e sobre o caráter constantemente violento da vida em cultura (Freud, 1908/1996; 1929/1996). A relação com o outro, o próximo, o vizinho, é por excelência uma relação de diferença, estranhamento (Freud, 1919/1996), embate e, quiçá, de luta. A renúncia pulsional, portanto, seria a dose necessária de perda, sustentada pela condição simbólica das relações sociais, que impedem (ou ao menos tentam impedir) a eclosão de um universo de puro gozo, sem limites, eventualmente, destrutivo, em todo caso, insuportável por definição. Esse gozo, para usar a terminologia lacaniana, não cessa de não se inscrever dada a impossibilidade constitutiva de resgate do objeto perdido (Freud, 1895/1996), embora retorne incessantemente "de fora", como Real, no interstício do Imaginário com o Simbólico, nas efêmeras apresentações do objet petit a (Lacan, 1972-3/1975). Em termos freudianos: esse gozo se impõe na realidade, com o grau de repetição e transtorno que the cabe. A diversão dos meninos que jogam com a violência gratuita acentua esse paradoxo entre brincadeira e morte, revelando um gozo que supera toda sorte de aparências, de expectativas imaginárias ou de qualquer convenção simbólica.

O filme é, portanto, expressão de um Real incontornável, ao passo que os aspectos simbólicos se mostram absolutamente ineficientes para fornecer uma versão mais completa da realidade por trás da abastada vida de uma família burguesa perfeita. Após o primeiro assassinato, Paul, o representante mais perverso da dupla de carrascos, apresenta uma retórica sarcástica a respeito dos motivos que os fazem matar. Para justificar sua maldade imotivada, remete-se à plateia usando argumentos existencialistas, sociológicos e psicológicos, todavia, esvaziando-os. Com esse recurso, Haneke desmonta qualquer possibilidade de explicação plausível. Embora Paul apresente motivos "justificáveis" que os levariam a matar cruelmente, vitimizando a história de vida do cúmplice, fala de forma extremamente irônica, desconstruindo qualquer justificativa teórica para os atos de crueldade. Ele desqualifica os argumentos intelectuais mais contundentes, para demonstrar algo absolutamente "factível", porque é humano, embora intangível, porque é inaceitável: a diversão com a violência. Aproxima então o espectador do matador, provocando seu desejo de vingança, ao levantar sua ferida ideológica, com um recurso inusitado: dá diversos sinais de que as vítimas escaparão. Inclusive, filma cenas em que os personagens têm chance de matar seus algozes. Em uma delas, filma 
a mãe, Anne, atirando em Peter o comparsa meio débil, porém Paul pega o controle da TV, volta a cena, e mostra o que "realmente" acontece: Peter atira na cabeça da criança. Assim, não há nenhuma redenção com o apaziguamento final, desejado pela audiência.

Nesse sentido, vemos a genialidade do autor/diretor, pois aborda a violência bruta sem referência ao encadeamento traumático que suas cenas produzem a posteriori, mas evocando aquilo que há de inexorável no desejo humano, ou seja, a vivência de um gozo em si, que jamais poderá ser completamente elaborado, revivido ou referendado. Esse gozo representa, em todo caso, uma violência estrutural. Segundo Žižek (2008), não basta olhar diretamente a manifestação da violência, tentando encontrar os componentes que subjazem à expressão traumática:

Há razões para se olhar de esguelha o problema da violência. Minha premissa de base é que há algo inerentemente mistificador em uma confrontação direta com isso: o horror avassalador de atos violentos e a empatia com as vítimas funcionam inexoravelmente como um engodo que nos impede de pensar. Um desenvolvimento conceitual desapaixonado da tipologia da violência precisa, por definição, ignorar seu impacto traumático ${ }^{4}$ (Žižek, 2008, p. 4, tradução livre).

Nesse sentido, aquilo que se configura como aterrorizante em Funny games é justamente uma violência apresentada diretamente, mas que precisa ser vista de viés, pois não quer dizer nada do que a priori nos motiva emocionalmente.

Façamos, pois, uma pequena digressão para tentar definir, ainda que sumariamente e em parte, o objeto pequeno $a$ na teoria lacaniana. $\mathrm{O}$ objeto $a$ adquire inúmeras características ao longo da obra de Lacan: aquilo que suscita angústia mas que ao mesmo tempo "causa" o desejo (Lacan, 1962-3/2005); o objeto da pulsão escópica e sua

3 Refiro-me aqui, respectivamente, aos aspectos da teoria do trauma em Freud (1895/1996) e em Lacan (1972-3/1975). Na primeira tópica freudiana está presente a compreensão de que o trauma só se define pelo encadeamento de cenas no decorrer do tempo, de modo que o trauma não pode ser reduzido à "primeira cena" em si (que aqui eu condensaria no filme como um todo), pois requer uma ressignificação, après coup, após o golpe do recalcamento e sua evocação por meio de outra cena familiar. Talvez só alguns dias, meses ou anos após sair do cinema advenha a angústia que retorna das cenas do filme em imagens de nosso cotidiano... O filme se aproxima mais da segunda tópica freudiana, com a concepção da pulsão de morte como compulsão à repetição, estruturada justamente sobre a análise de uma brincadeira infantil, o fort- $d a$, como tentativa de elaborar o trauma (Freud, 1920/1995). Do ponto de vista lacaniano, evoco o aspecto Real do trauma, naquilo que torna impossível sua transcrição em palavras ou imagens, mas que diz respeito a algo que se passa no corpo, um gozo mórbido, inescapável, inviável, mas por isso mesmo insistente e repetitivo, que ataca o sujeito de fora e o desestrutura.

4 Original: "There are reasons for looking at the problem of violence awry. My underlying premise is that there is something inherently mystifying in a direct confrontation with it: the overpowering horror of violent acts and empathy with the victims inexorably function as a lure which prevents us from thinking. A dispassionate conceptual development of the typology of violence must by definition ignore its traumatic impact". função de anamorfose (Lacan, 1964/2008); o lugar de desejo que o analista ocupa, mas o fato de poder se constituir como um resto, abjeto, no final da análise; o que enlaça os três registros Real, Simbólico e Imaginário, embora escape a todos eles (ver Guedes, 2010; Arreguy, 2012); um mais de gozar em confluência com o feminino não todo, que remete por sua vez ao vazio estruturante do desejo (Lacan, 19723/1975). Nas palavras de Lacan (1972-3/1975): "O objeto a vem a funcionar em relação a essa perda" (p. 40), ou seja, salientando um furo ou uma falha na cadeia significante. Remontando à teoria freudiana, podemos relacioná-lo ao Niederkommenlassen, quando Freud (1920a/1996) descreve uma cena de passagem ao ato da jovem homossexual que está analisando. Ao atirar-se na linha do trem, a jovem assinala algo que "precisa cair", suscitando a precipitação de um ato endereçado ao seu pai. Essa situação evoca o regime das pulsões parciais, em que algo se destaca da cena (ela se joga para fora da cena), ou que cai do corpo (Freud, 1905/1996), quando pensamos a perda das mais diversas secreções. Por exemplo, as fezes, a urina, a ejaculação, o sangue, as lágrimas, os bebês ou tudo que faz parte da corporeidade, mas que também é destacável e se perde de si para o mundo, enfim, o que cai do corpo. Esse vazio causado pela perda, porém, constitui o sujeito em sua mais absoluta essência desejante. Lacan (1964/2008) rememora que existe ... uma correspondência das formas diversas do objeto a com a função central e simbólica do menos- $f i$... (p. 26). Nesse sentido, a imagem de pedaços decaídos do corpo tem o poder paradoxal de estimular a angústia e o desejo, além de enunciar uma falta constitutiva que, em certa medida, se correlaciona com a morte. Acentuando a dimensão da perda e do vazio, que também pode estar relacionada à pulsão escópica, salientamos a importância da seguinte definição de Lacan (1964/2008):

O olhar pode conter em si mesmo o objeto $a$ da álgebra lacaniana, no qual o sujeito vem a fracassar, e o que especifica o campo escópico e engendra a satisfação que lhes é própria, é que lá, por razões de estrutura, a queda do sujeito fica sempre despercebida, pois ela se reduz a zero. Na medida em que o olhar, enquanto objeto a, pode vir a simbolizar a falta central expressa no fenômeno da castração, e que ele é objeto $a$ reduzido, por sua natureza, a uma função punctiforme, evanescente - ele deixa o sujeito na ignorância do que há para além da aparência. (Lacan, 1964/2008, p. 80, grifos meus)

E não seria essa a genialidade de Haneke no filme: expor a plateia à absoluta castração posta pela sombra do objeto $a$ presente em algumas cenas de morte? Ao olhar a morte de frente ou prever a queda mortal do corpo, não estaríamos nos "divertindo" com a "visão" do objeto $a$ ? Pelo privilégio da dúvida, até que ponto gozo e alienação se interpõe com uma forma de sublimação passiva do espectador?

Volto ao enredo, no intuito de trabalhar a imagem espacializada do corpo como signo do objeto a, que se encontra no mundo, e aparece em Funny games enquanto signo da evanescência entre vida e morte, apenas captada 
num átimo pelo olhar. O primeiro assassinato ocorre num deslocamento da cena. Paul ordena que Peter escolha um dos personagens e mate-o. Em seguida, vai para a cozinha preparar tranquilamente um sanduíche, enquanto o som do disparo do rifle e os gemidos dos pais fertilizam a imaginação do espectador. A voz, o pranto e os urros de pavor produzem um halo sepulcral que destoa fortemente da displicência do ato de cantarolar e comer do carrasco. O corpo do menino é reconfigurado no espaço como se vê no plano subsequente, em que a televisão e a parede estão totalmente sujas, respingadas com o resto abjeto dos miolos estourados da criança. A tomada é extremamente lenta, sugerindo uma paralisação do tempo, impondo um non-sense à ação. A mãe, com mãos e pernas atadas, com muita dificuldade, alcança a televisão e desliga o aparelho, que passava uma corrida de carros, cujo som estridente também destoa do momento, irritando os ouvintes. O som da TV desmistifica e dessacraliza o instante da morte, tornando-a banal, apenas mais um fato passageiro como qualquer outra circunstância sem densidade da vida cotidiana, noticiada e consumida sem muita escolha. É como se aquele ruído impedisse a instalação do ambiente severo da morte, daí sua intensidade mais traumática, com efeitos de desmentido (Ferenczi, 1933/2011; 1934/2011). Ora, sob a pena de um abuso epistemológico, é importante fazer menção a outro paradigma do trauma, para vislumbrar, ainda que de esguelha, um resgate do aspecto produtivo, sublimatório e criativo propiciado por essa produção artística. Em meio a todas essas contradições, pode-se pensar que "o que torna qualquer narrativa do trauma verdadeira é sua tão factual independência, sua confusão, sua inconsistência" (Žižek, 2008 , p. 4,$)^{5}$. O que vai ser elaborado a partir do contato com a cena é imponderável, mesmo que seus efeitos traumáticos sejam inevitáveis. Do lado da cena, ao apresentar o abjeto do som do assassinato sem cena e a exposição do dejeto corporal sem sujeito, Haneke oferece um relance do objeto a (Lacan, 1964/2008), a anamorfose que sugere algo além do apresentado, embora jamais apreensível pelo espectador. Nesse sentido, é possível afirmar que Haneke, assim como faz em outras obras magistrais como $A$ professora de piano (2001), A fita branca (2009) e Amor (2013), é capaz de apreender com sua obra, e, em especial em alguns fragmentos de cenas, a angústia e a dor do contemporâneo, lançando luz sobre aquilo que Agambem (2006/2010) definiu como "a sombra de seu tempo". A capacidade de vislumbrar a densidade imaterial do que é contemporâneo é definida da seguinte maneira pelo autor:

O contemporâneo não é apenas aquele que, percebendo o escuro do presente, nele apreende a resoluta luz; é também aquele que, dividindo e interpolando o tempo, está à altura de transformá-lo e de colocá-lo em relação com outros tempos, de nele ler de modo inédito a história, de "citá-la" segundo uma

5 Original: "What renders a report of any narrative of trauma truthfull is its very factual unreliability, its confusion, its inconsistence" . necessidade que não provém de maneira nenhuma do seu arbítrio, mas de uma exigência a qual ele não pode responder. É como se aquela invisível luz, que é o escuro do presente, projetasse a sua sombra sobre o passado, e este, tocado por esse facho de sombra, adquirisse a capacidade de responder às trevas do agora. (Agamben, 2006/2010, p. 72)

A brincadeira de matar "educadamente" iniciada e cruelmente concebida pelos dois algozes nos coloca diante de um aspecto contraditório do sintoma cultural contemporâneo. Ora, tanto os filmes de ação violenta, quanto os jogos interativos de matar são extremamente populares entre jovens, tornando muitos deles campeões nas tecnologias do irascível. Mas isso não é só de hoje, e sobretudo, inclui uma promessa sombria de futuro. Ou, quem sabe, teríamos que inverter essa proposição, entendendo que a única forma, ou talvez a mais prática, de elaborar os restos da violência na realidade seja brincando com ela na ficção? O filme, portanto, representa de modo tácito o contemporâneo, mas estendese de modo complexo ao que há de universal, projetando-se no passado e antecipando o incontornável futuro, pela perenidade da diversão com os jogos de violência humana. Há de se considerar que o filme foi gravado em duas versões, cujo roteiro é idêntico, em 1997 e 2007, em dois diferentes países, Estados Unidos e Alemanha, mas produz impactos muito semelhantes independente do lapso de tempo que os separa. Algo, portanto, do sintoma cultural perverso permanece.

No livro, Primeiro como tragédia depois como far$s a$, Žižek (2009/2011) questiona os sistemas capitalista e comunista, chegando à conclusão de que devemos tomar cuidado com aquilo que desejamos. Recentemente, ouvi um relato de um rapaz que retrucava aos pais, quando demandavam que fosse alguém na vida, que saísse da frente da tela, que parasse o jogo. O rapaz, que passava horas, diariamente, na internet, em um desses videogames de luta armada, respondeu: "Aqui eu sou alguém, aqui eu sou o melhor!" Afinal, o desejo de excelência advindo do Outro, no capitalismo tardio intrinsecamente associado ao imperativo de gozo, se realizava bem ali, na destrutividade aclamada, premiada e viabilizada pela interação com a tela. Destruição originada e destinada à mesma sociedade de consumo que a produz. Com efeito, a diversão mobilizada pelas técnicas de destrutividade e pela atuação/sublimação do ódio não seria parte inerente de um sintoma social? Nesse sentido, a tradução "violência gratuita" seria de fato um sinônimo para "jogos de diversão". Em que medida esses jogos seriam "nocivos" para nossa juventude? Qual sua função social no contemporâneo? Certamente, nos filmes ideológicos esses jogos seriam a garantia de manutenção do status quo. Já em Funny games, a dureza dos jogos de cena apontaria uma chance de distanciamento, criando uma condição de crítica, sobretudo por manipular quebras na ficção, paradoxalmente, tornando-a mais verdadeira, encarnada, Real. Ao encenar o sombrio, o filme "lança luz sobre a sombra de nossos tempos". 
Adorno (2002), desde a primeira metade do século $\mathrm{XX}$, já caracterizara a indústria cultural como entertainment ou, ainda, indústria da "diversão" atrelada ao consumo e à manipulação das massas:

A violência da sociedade industrial opera nos homens de uma vez por todas. Os produtos da indústria cultural podem estar certos de serem jovialmente consumidos, mesmo em estado de distração. Mas cada um destes é um modelo do gigantesco mecanismo econômico que desde o início mantém tudo sob pressão, tanto no trabalho quanto no lazer, que tanto se assemelha ao trabalho. (p. 19)

Esse dispositivo da indústria cultural continua a operar, porém, de modo ainda mais profundo na sociedade virtual pós-repressiva, já que lazer e trabalho devem ser identificados, e produzir os mesmos efeitos, na medida em que seus objetivos se igualam (Žižek, 2006/2009). Deleuze (1992/2010), ao caracterizar a "sociedade de controle", enfatiza o caráter fragmentário do sujeito, posto que é um "divíduo" (e não mais um indivíduo), uma "cifra" absorvida pela máquina, cuja ação permanente, na formação, no lazer e no trabalho, com a redução da temporalidade ao "tudo ao mesmo tempo agora já", praticamente inviabilizam o raciocínio crítico, que só opera num nível identificatório. A "diversão" ou "distração", como proposta por Adorno, apresenta necessariamente uma estética de gozo que engaja o espectador na cena, não importa qual resultado possa tirar de seu lazer, que passa a ser um veículo de violência a ser passivamente usufruída. A violência no plano da arte pode ser esteticizada e consumida, haja vista a nova onda jovem de se fantasiar de zumbi em festas, a reinvenção do punk, do trash, o modismo de portar caveiras nas mais variadas estampas da moda, a multiplicação de tatuagens mórbidas, o uso de piercings etc., dialeticamente marcando crítica e adesão ao status quo midiático.

No ensaio crítico sobre Violência e mídia, Haneke (2010) desinveste a clássica pergunta se a mídia representa a realidade da violência de nossa cultura ou se é ela quem a produz, classificando essas questões como um falso problema. Colocada em termos psicanalíticos, poderíamos retomar a questão: a violência no cinema promove uma função sublimatória ou pode desencadear mecanismos perversos? Esse par antitético talvez esteja mal posto, na medida em que os afetos suscitados no espectador são fora de controle. E, independentemente do critério do "gosto", ou seja, "do prazer" que uma narrativa fílmica evoca no espectador, há algo traumático que ela pode apresentar pela pura repetição de um ciclo vicioso.

Assim, para tratar da conexão entre a dimensão perversa subjacente ao laço social e a simples brincadeira subjetiva adepta à diversão com o horror, usamos palavras de consenso sobre o filme: " $O$ filme frequentemente borra a linha entre ficção e realidade, especialmente iluminando 0 ato de observação". Ao ativar a pulsão escópica, o filme também borra as fronteiras entre o ato subjetivo e a responsabilidade social que promove mais violência. A apresentação realística do filme coloca o espectador em estado de descrença, ao mesmo tempo que acentua dialeticamente a realidade extrema dos fatos que apresenta. Fatos que fazem parte de nosso cotidiano e que, de certo modo, nos constituem como sujeitos contemporâneos. Encerro ainda interrogando, em que medida somos responsáveis pela violência que se reproduz por meio da arte (ou da subarte que consumimos)?

6 Tradução direta do original: The film frequently blurs the line between fiction and reality, especially highlighting the act of observation. Disponível na internet: http://en.wikipedia.org/wiki/Funny_Games_\%281997_film\%29

\section{The aesthetics of entertainment in the contemporary "living dead"}

Abstract: This essay aims to reflect on the fun with an aesthetic of violence in cult movies and some of its effects in contemporary subjectivity. It is based on some concepts of psychoanalytical theory in combination with the critical perspective of Theodor Adorno. The text makes use of the concept of diversion (at the same time as fun, entertainment, distraction or its opposite: deviation) as a source of criticism of the cultural industry, in order to demonstrate how certain aesthetic of violence produces a passive sublimation and, in a certain way, alienates many subjects, mainly at the political point of view. They represent a sort of "undeads", or helplesslies zombies, as demonstrated by the analysis of Slavoj Žižek. The movie Funny Games by Michael Haneke ilustrates this analysis.

Keywords: diversion, violence, living-death / undead, psychoanalysis, cult movies.

\section{Esthétiques d'amusement sur les «morts-vivants» contemporaines}

Résumé : Cet article a le but de réfléchir sur l'amusement avec une esthétique de violence dans les cult movies et certains de ses effets sur la subjectivité contemporaine. La discussion s'appuie sur le référentiel psychanalytique rassemblé sous la perspective critique de Theodor Adorno. Le texte fait usage de la notion d'amusement comme une source de critique de l'industrie culturelle, afin de démontrer comment une certaine esthétique de violence génère la sublimation passive et aliénante sur de 
nombreux sujets, qui représentent, principalement du point de vue politique, une sorte de «morts-vivants», ou zombies impuissants, comme en témoigne I'analyse de Slavoj Žižek. Le film Funny Games de Michael Haneke illustre cette analyse.

Mot-clés: amusement, violence, morts-vivants, Psychanalyse, cult movies.

\section{Estéticas de la diversión en los “muertos-vivos" contemporáneos}

Resumen: Este ensayo tiene como objetivo reflexionar sobre la diversión con una estética de la violencia en los cult movies y algunos de sus efectos en la subjetividad contemporánea. Se basa en el Psicoanálisis según la perspectiva crítica de Theodor Adorno. El texto hace uso del concepto de diversión como fuente de crítica a la industria cultural, con el fin de demostrar cómo cierta estética de la violencia produce una sublimación pasiva y alienante en muchas personas que van a representar, principalmente del punto de vista político, una especie de "muertos vivos", o zombies que no pueden hacer nada, como lo demuestra el análisis de Slavoj Žižek. La película Funny games [Horas de terror] de Michael Haneke ilustra este análisis.

Palabras clave: diversión, violencia, muertos vivos/no muertos, psicoanálisis, cult movies.

\section{Referências}

Adorno, T. (2002). Indústria cultural e sociedade. São Paulo, SP: Paz e Terra.

Agamben, G. (2010). O que é o contemporâneo e outros ensaios. Chapecó, SC: Argos. (Trabalho original publicado em 2006)

Arreguy, M. E. (2012). A diversão com a dor no cinema pop violento. Cadernos de Psicanálise, 34(27), 43-64.

Birman, J. (2012). O sujeito contemporâneo. Rio de Janeiro, RJ: Civilização Brasileira.

Deleuze, G. (2010). Conversações. São Paulo, SP: Editora 34. (Trabalho original publicado em 1992)

Ferenczi, S. (2011). Confusão de língua entre os adultos e a criança. In Obras completas. Psicanálise IV. São Paulo, SP: Martins Fontes. (Trabalho original publicado em 1933)

Ferenczi, S. (2011). Reflexões sobre o trauma. In Obras completas. Psicanálise IV. São Paulo, SP: Martins Fontes. (Trabalho original publicado em 1934)

Freud, S. (1996). Projeto para uma psicologia científica. In S. Freud, Edição standard brasileira das obras psicológicas completas de Sigmund Freud (Vol. 1). Rio de Janeiro, RJ: Imago. (Trabalho original publicado em 1895)

Freud, S. (1996). Três ensaios sobre a teoria da sexualidade. In S. Freud, Edição standard brasileira das obras psicológicas completas de Sigmund Freud (Vol. 7). Rio de Janeiro, RJ: Imago. (Trabalho original publicado em 1905)

Freud, S. (1995). Moral sexual civilizada e doença nervosa moderna. In S. Freud, Edição standard brasileira das obras psicológicas completas de Sigmund Freud (Vol. 9). Rio de Janeiro, RJ: Imago. (Trabalho original publicado em 1908)

Freud, S. (1996). O estranho. In S. Freud, Edição standard brasileira das obras psicológicas completas de Sigmund Freud (Vol. 17). Rio de Janeiro, RJ: Imago. (Trabalho original publicado em 1919)
Freud, S. (1995). Além do princípio do prazer. In S. Freud, Edição standard brasileira das obras psicológicas completas de Sigmund Freud (Vol. 19). Rio de Janeiro, RJ: Imago. (Trabalho original publicado em 1920)

Freud, S. (1995). A psicogênese de um caso de homossexualismo numa mulher. In S. Freud, Edição standard brasileira das obras psicológicas completas de Sigmund Freud (Vol. 19). Rio de Janeiro, RJ: Imago. (Trabalho original publicado em 1920a)

Freud, S. (1996). Mal-estar na civilização [cultura]. In S. Freud, Edição standard brasileira das obras psicológicas completas de Sigmund Freud. Rio de Janeiro, RJ: Imago. (Trabalho original publicado em 1929)

Gondar, J. (2013). Ferenczi e o sonho. Cadernos de Psicanálise, 35(29), 27-39.

Guedes, D. de F. P. (2010). Uma introdução ao conceito de objeto a. Psicanálise \& Barroco em revista, 8(1), 159-174.

Haneke, M. (2010). Violence and media. In R. Grundmann, A companion to Michael Haneke. Hong Kong, HK: Wiley Blackwell.

Jameson, F. (1993). O pós-modernismo e a sociedade de consumo. In E. A. Kaplan, O mal-estar no pósmodernismo. Rio de Janeiro, RJ: Jorge Zahar. (Trabalho original publicado em 1990)

Kaufmann, P. (1996). Dicionário enciclopédico de psicanálise: o legado de Freud e Lacan. Rio de Janeiro, RJ: Jorge Zahar. (Trabalho original publicado em 1993)

Lacan, J. (1975). Encore. Livre 10. Paris: França: Seuil. (Trabalho original publicado em 1972-1973)

Lacan, J. (2005). O seminário. Livro 10: a angústia. Rio de Janeiro, RJ: Jorge Zahar. (Trabalho original publicado em 1962-1963) 
Lacan, J. (2008). O seminário. Livro 11: os quatro conceitos fundamentais da psicanálise. Rio de Janeiro, RJ: Jorge Zahar. (Trabalho original publicado em 1964)

Massat-Hessel, H. (2006). De la cause commune a la fosse commune. Psychanalyse et Roman Noir. Master 2 Recherche, anthropologie psychanalytique et clinique $d u$ corps (P.-L. Assoun, dir.). Paris: UFR Sciences Humaines Cliniques, Université Denis Diderot.
Žižek, S. (2008a). Órgãos sem corpos: Deleuze e consequências. Rio de Janeiro, RJ: Cia. de Freud.

Žižek, S. (2008). Violence. New York, NY: Picador.

Žižek, S. (2009). Lacrimae Rerum: ensaios sobre cinema moderno. São Paulo, SP: Boitempo. (Trabalho original publicado em 2006)

Žižek, S. (2011). Primeiro como tragédia depois como farsa. São Paulo, SP: Boitempo. (Trabalho original publicado em 2009) 